\title{
Implementation of an Effective Bus Pass Generation and Renewal Application
}

\author{
Niteesh Joshi $^{1}$, Mahesh Waghmare ${ }^{1}$, Sujeet Bhosale ${ }^{1}$, Ankit Singh ${ }^{1}$, Sunita Nandgave ${ }^{1}$ \\ G. H. Raisoni College of Engineering and Management, Pune ${ }^{1}$
}

\begin{abstract}
Android is the latest and a rapid growing technology available for all the users or customers in now days market. This project is mainly aims to provide an effective facility of bus pass through mobile Application. It also uses database to store data about passenger. This system has two logins, one for user side and another for admin side. In this project bus pass generation as well as renewal system has been provided. It is mobile application which is build using Angular JS and IONIC framework. Ionic is one of the best frameworks used to develop application now days. Angular JS and Ionic provide most custom methods and components to interact with application. Now days Ionic 2 support the universal windows platform for building windows 10 applications. It is an android application for people to get bus pass through online which is very useful as it reduces paper work, time consuming and makes process in simple and faster way. User can renew their existing pass by extending their validity of time when pass expires. Admin can view all the details and balance of user through its login. This system was intended to develop a mobile application to perform functions like accessing information for authentication and provide pass to particular person. So, users don't need to stand in queue for long time. This system is helpful for people to get a pass. User can get a pass from anywhere and anytime. There is no need to do manual process. The benefit of this project is no one can reuse issued pass due to photograph and unique id. The notification will generate before expiring monthly pass. This is beneficial for every passenger to get pass in time. The one time password will be generated for every user while registering first time. Aim of this system is to generate daily and monthly bus pass.
\end{abstract}

Keywords: Angular JS and IONIC framework, Bus Pass Generation, Ionic 2.

\section{INTRODUCTION}

We are creating this project using IONIC framework to provide "safe, reliable, time saving, efficient, comfortable and affordable" services for people, although the cost for providing this service has been substantial. IONIC framework is one of the popular and important technologies now a day. It is heavily subsidized by the government and is reportedly in the red, like most of India's state run road transport undertakings. Even though we have lot of technology development in Pune, we have an official application for Bus Pass Registration and Renewal as many of our Neighbor states possess.[1]

Hence we got this idea that would help our people in a better way. As per the previous system of our state people had to do each and every process manually, but this system helps people to make the work a bit faster.[2] Customer can register for the Bus Pass over the Internet, within the first 15 days of the month. Furthermore, customers no need to pay cash to buy bus pass because they can pay the amount using Credit Card.[3]

Hence, there is a need of reformation of the formal system with more advantages and flexibility. Because of the drawbacks that are present in the existing system, we got this idea that would help people in a better way.[5]

Customer can buy the bus pass over the Internet, 24 hours a day throughout the week, this solves the issue of bus ticket being misplaced or stolen. Hence, there is a need of reformation of the system with more advantages and flexibility. The Bus Scheduling and Booking System eliminate most of the limitations of the existing software.[5]

\section{RELATED WORK}

Online Bus pass Generation system is already implemented by Maharashtra State Road Transport Corporation . The only drawback is the pass application is available for ticket reservation only .So this Bus pass Generation system is helpful as it reduces the daily ticket reservation , time consumption and makes the process of getting Bus pass simple and fast.

An application has been implemented in Pune, named "Pune Bus Guide". This application gives the way to the destination correctly, but the number of drawbacks that it has is greater than the number of advantages. 


\section{PROPOSED SYSTEM}

We are creating this project to overcome the problems of existing system. In this project we are using IONIC framework which latest technology in the IT Field. As it has number of advantages over other technologies. User can generate online form. User can show his/her pass online also, there is no need to take print of that pass. User can do online payment with better security. They can use credit card or debit card for transaction.

Steps involved in maintaining the user/client information in the database:

- Step 1. Login

- Step 2. Application for Forms Authentication.

- Step 3. Develop functions to generate Hash Value.

- Step 4. User account database.

- Step 5. Store account details in database.

\section{MODULE DESCRIPTION}

There are several modules:-

1) Registration module

2) Login and change password.

3) Apply.

4) Check application and Issue pass.

5) Online Payment.

6) Pass generation.

7) Notification (message alert).

We are referring screenshots of Karnataka State to implement our system.

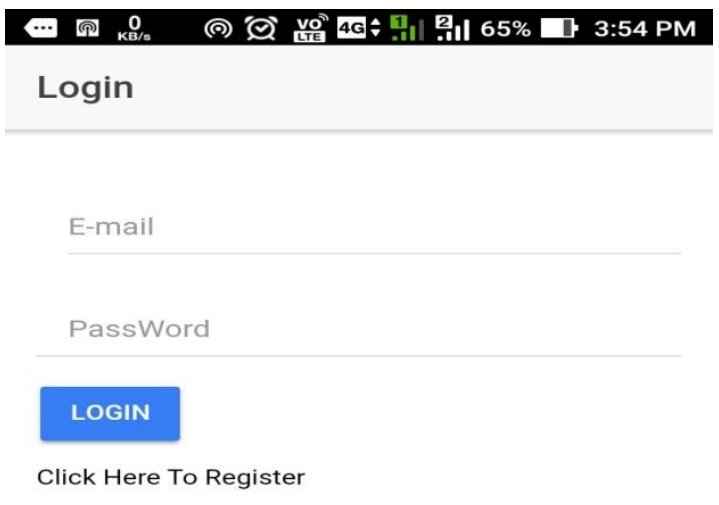

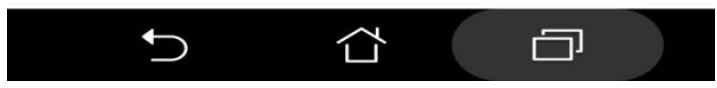

Fig1. Home Page

In Fig1, for now Login page is our home page. We took reference of Karnataka State for our application. This is the home page of our application. We took side bar which is mostly used in IONIC Framework. This is very easy way to user to handle this application. Side bar contains all the fields which are required in our system like home, login, register, about. In this applications payment can be done through internet. We are implementing this feature in our system. 
International Journal of Advanced Research in Computer and Communication Engineering ISO 3297:2007 Certified

Vol. 6, Issue 5, May 2017

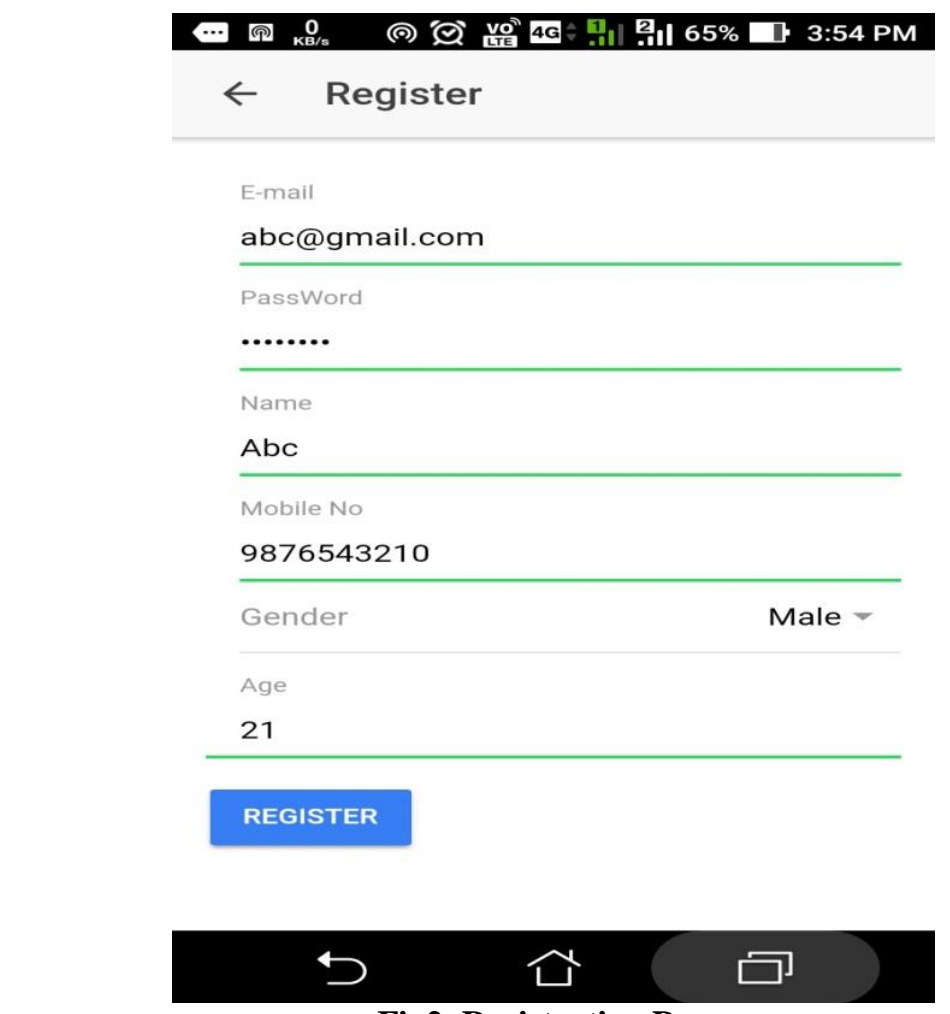

Fig2. Registration Page

The user needs to register by providing all information of given fields which are shown in Fig. 2

User has to create his/her password. In this registration, User has to create password and user name for further process.

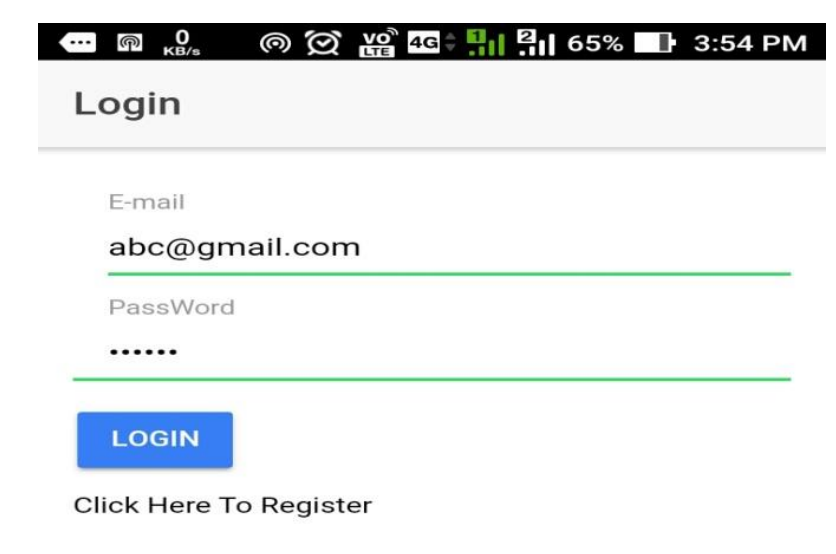

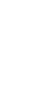

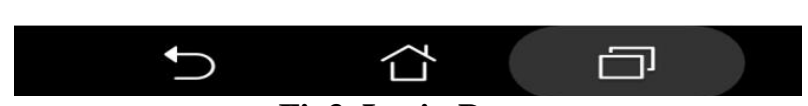

Fig3. Login Page

In Fig.3, after registration, the user can login to system by using username and password which is created in registration form. If the password is incorrect then it will give message and user should retype username and password. 


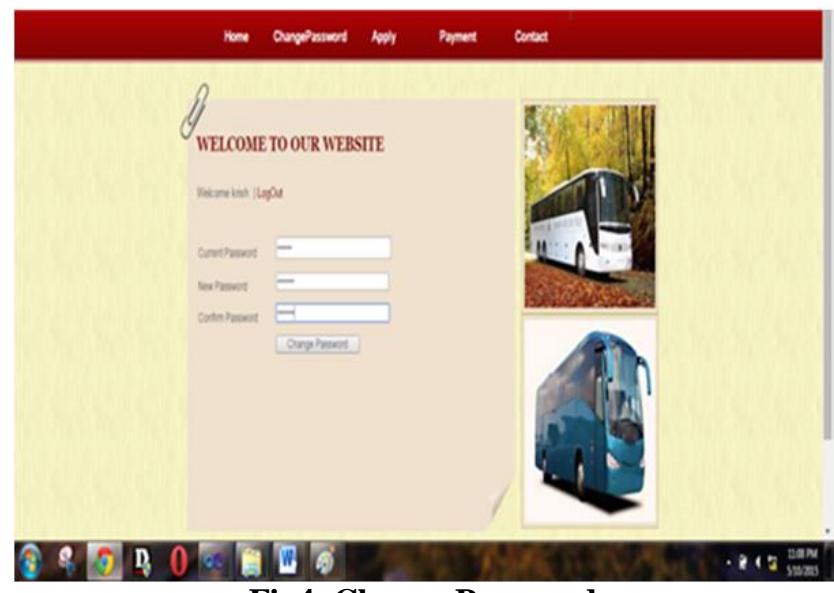

Fig4. Change Password

In Fig.4, Changing password option is also provided. If users want to change password, they need to provide current and new password to conform password. The password will in encrypted format.
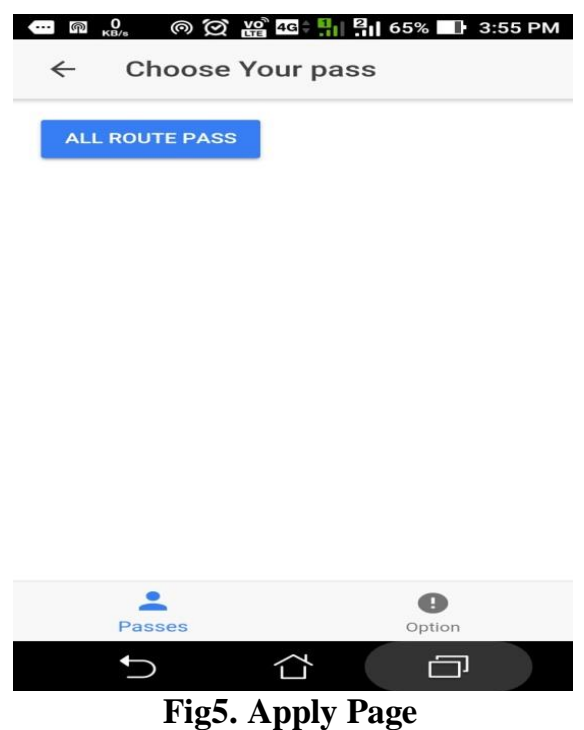

In Fig.5, After Login, user has to apply for the form by providing necessary details to get the pass. In this user has to write all the information like date, place, Id proof. In this page, first user should select type of pass i.e. 1 day pass or monthly pass. After that he can fill up the necessary details.
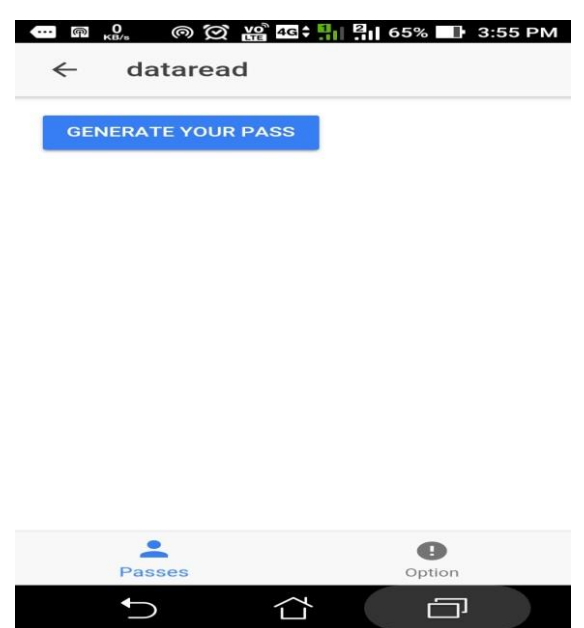

Fig6. Generate and issue pass 
In Fig.6, Admin can check received pass application and verify then issue the pass. Then admin can do further process. Admin checks whether that person is eligible or not.

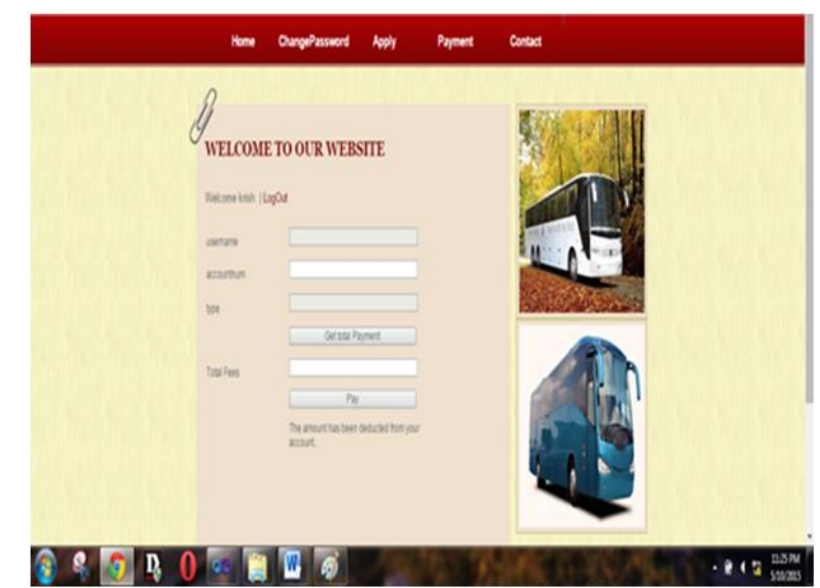

Fig.7 Online Payment

In Fig.7, Online payment process is most important process in this, the fixed amount will be deducted from user's account when user click submit button and do the verification as well. User can also give money to conductor without doing online payment. User needs to do online payment for security purpose.
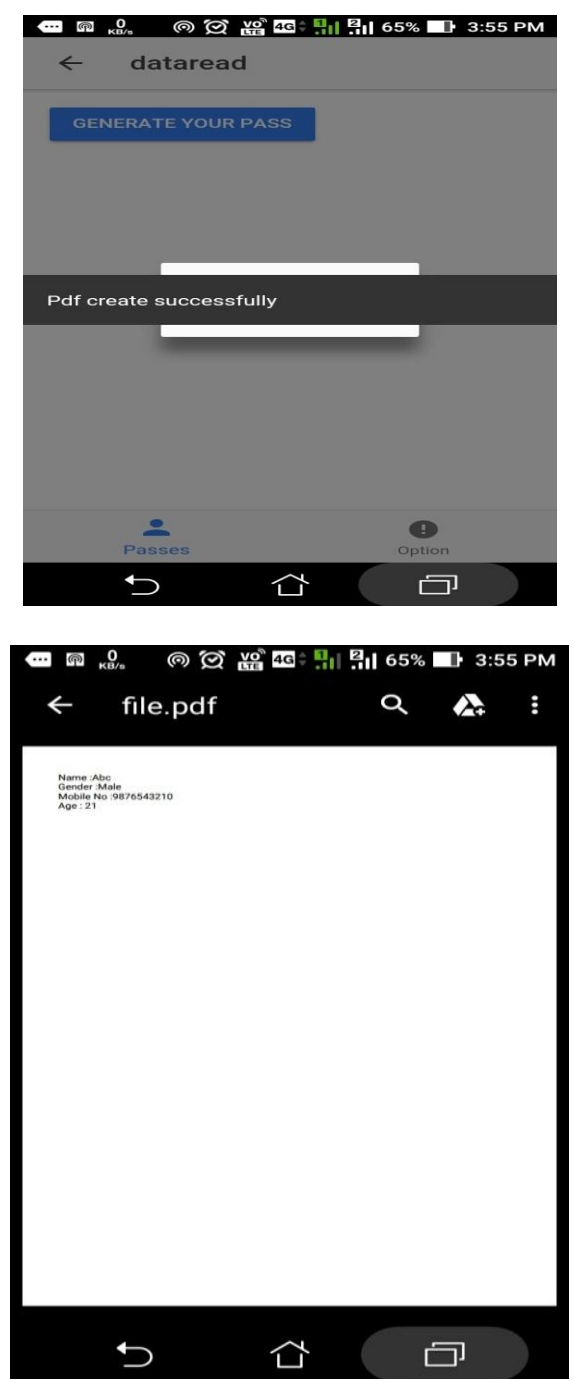

Fig.8 Generated pdf 
In Fig.8, The pass will be generated in the form of pdf which consist of logo of depot and the photo of applicant. In pass, the information is display which consists of name of applicant, source and destinations, date of pass issue and expiry of pass. Renewal of pass is also made. The generated pdf will be proof of passenger.

\section{CONCLUSION}

This is very useful project for public who are facing problem with manual work of bus pass. It is a real time project for registration and renewal of bus pass. It also help people by providing or sending a message or mail before completion of his or her bus-pass validity. The registration and renewal can be done using online payment. In this project the new requirement can be easily added or changed by the Admin. Following changes can be updated by the admin First is admin can view new route information as well as fare can be calculated i.e. payment system can be improved or updated.

\section{REFERENCES}

[1] A Mobile Application for Bus Information System and Location Tracking using Client-Server Technology,( Yasha Sardey, Pranoti Deshmukh, Pooja Mandlik, Saurabh Shelar, Minal Nerkar.)

[2] Online bus pass renewal system using web application.( N. Nandhini, S. Pavithra, E. Sangavi, K. Aravindhan)

[3] Online Bus pass system for G.S.R.T.C.( Patel Reshma K, Chaudhary Neha B)

[4] Development of an effective bus pass generation system for transportation system in Karnataka state. (Parashuram Baraki, Sandhya Kulkarni, Spurthi Kulkarni, Arpita Goggi, Keerti priya.) I

[5] Google Play Store details "Pune Bus Guide" - https://play.google.com/store/apps/details?id=com.Appsimplify. punebus

[6] Google Play Store details “M-Indicator Mumbai”-https://play.google.com/store/apps/details?id=com. mobond. mindicator

[7] Google Play Store details "Delhi Bus Navigator" - https://play.google.com/store/apps/details? id=com. hashtag. Delhibusnavigator

[8] “An Expert System for Tourists using Google API”(Aleksandar ,Pejic; Szilveszter, Plet,)

[9] "Location Based Services using Android Mobile Application"(Amit Kushwaha, Vineet Kushwaha,) I

[10] "Research on Development of Android Applications", (Jianye Liu, Jianaun Yu,)

[11] "Development Environment for Android Application Development: an Experience Report"(Robi Grgurina, Goran Brestovac and Tihana Galinac Grbac,)

[12]Mobile application for e-bus pass renewal system for tamil nadu publictransport system.(M.S.Saravanan, A. Praveen Kumar) 